\title{
The energy challenge
}

\author{
Chris Llewellyn Smith
}

Received: 27 July 2012/Accepted: 31 July 2012/Published online: 18 August 2012

(C) The Author(s) 2012. This article is published with open access at Springerlink.com

\begin{abstract}
This paper provides an overview of the enormous challenge of meeting future energy demand in an environmentally responsible manner. A portfolio approach is required, which must include more solar, wind, hydro, bio and marine energy wherever sensible, and demand reduction (through better planning, especially in the world's expanding cities), increased efficiency, more nuclear power, and (if feasible, safe and economically competitive) carbon capture and storage. In the longer term, the world will need much more solar power, advanced nuclear fission, and fusion power-if it can be made to work reliably and competitively. The policy priority is to put a (high) price on carbon in the context of a global agreement (through a tax, or cap and trade with a floor price to provide certainty for investors), which is easily said, but very hard to do.
\end{abstract}

Keywords Energy demand · Energy supply · Energy efficiency · Fossil fuels · Renewable energy · Nuclear energy

\section{Introduction}

The biggest challenge of the twenty-first century is to provide sufficient food, water, and energy to allow everyone on the planet to live decent lives in decent environments, in the face of rising population, the threat of climate change, and (sooner or later) declining fossil fuels. Provision of sufficient energy is a necessary (but not sufficient) means to meet the overall challenge.

C. Llewellyn Smith $(\bowtie)$

Oxford University, Oxford, UK

e-mail: c.llewellyn-smith@physics.ox.ac.uk
The world is using energy at a rate of $2.4 \mathrm{~kW}$ per person: that is the equivalent of 24 old-fashioned $100 \mathrm{~W}$ incandescent light bulbs burning continuously for every man woman and child on the planet. Average use per person is $10.4 \mathrm{~kW}$ in the USA while it is only 0.21 in Bangladesh. The average is $4.6 \mathrm{~kW}$ in the UK and in the Middle East as a whole, although it is much higher in the Gulf Cooperation Council (GCC) countries. For everyone to use energy at the same rate as the average person in the UK or the Middle East, total energy consumption would have to go up 1.9-fold today, or 2.4-fold when the population reaches 9 billion. This is probably impossible so changes in behaviour and expectations will be necessary.

Some $78 \%$ of the world's primary energy is currently generated by burning fossil fuels (oil, coal, gas) which is causing potentially catastrophic climate change, and horrendous pollution, and is unsustainable as they won't last forever. The rest (in thermal equivalent terms) is provided by: burning combustible renewables and waste-10\%; hydropower-5.8\%; nuclear power-4.7\%; geothermal + solar + wind + marine power $-1.2 \%$. The popular hope that the last category might replace fossil fuels must be tempered by the realisation that to do so its contribution would have to increase by a factor of 65 , and the increase would have to be even greater in the future assuming world consumption continues to grow, driven by (very welcome) economic development in China, Africa and India.

The scale of the challenge is also shown by the International Energy Agency's 2011 'new policies scenario'. According to this scenario, which assumes the successful implementation of all agreed national policies and announced commitments designed to save energy and reduce use of fossil fuels, energy use will increase $33 \%$ in the period 2010-2035, while the use of fossil fuels will 
increase $23 \%$ (the increases come almost entirely from non-OECD countries). Although this falls far short of expectations, and of what is needed to temper climate change, the scenario requires very demanding measures, such as a $70 \%$ increase in nuclear power and $60 \%$ more hydropower (think of the civil engineering). Most commentators anticipate larger increases in energy use, e.g. the BP Energy Outlook 2030 (published in early 2012), which is based on BP judgement of what will actually happen and is not a business as usual extrapolation, projects a $39 \%$ increase by the earlier date 2030, with fossil fuels up $31 \%$.

\section{Future of fossil fuels}

There is said to be a Saudi saying: "My father rode a camel. I drive a car. My son flies a plane. His son will ride a camel". Could this be true?

It is observed, and understood, that conventional oil production in a given region peaks when roughly half the primordial endowment of extractable oil has been produced. Predictions of when world oil production will peak depend on estimates of the primordial endowment and assumptions about how much it will be economic to extract, which in turn depend on assumptions about developments in technology and the oil price. A 2009 literature review by the UK Energy Research Centre concluded that the peak 'is likely to occur before 2030' and that there is a 'significant risk' that it will occur before 2020.

But there is plenty of oil in unconventional places (e.g. the deep ocean off Brazil and the arctic) and lots of unconventional oil (heavy oil, tight/shale oil, oil from oil shale or tar sands). Without significant technological developments, exploitation of most of these reserves will however be expensive and would be difficult to expand fast enough to compensate for an early peak in conventional oil production. The debate on the effect this will have on oil prices continues. Confidence in continued high prices would presumably lead to increased investments in turning coal and gas into oil.

There is plenty of coal and gas. According to the IEA, global coal reserves that are economically recoverable with current technology are enough for 150 years with current use, while there is enough recoverable gas for some 125 years, which potential unconventional resources could increase to 250 years. The fracking/shale gas revolution in the USA has had a dramatic effect on the world gas market, e.g. by freeing up liquefied natural gas (previously destined for the US) from Qatar, which in 2011 provided $27 \%$ of the UK's gas, up from less than $0.15 \%$ in 2008, and is a major contributor in the Far East. It is unclear, however, whether the expanding rate of production of shale gas is sustainable, and how much is really going to be accessible.

\section{Climate change and carbon capture and storage}

Climate scientists tell us that it would take thousands of years for the level of carbon dioxide in the atmosphere to drop to preindustrial levels were carbon emissions to stop abruptly. It follows that on time scales shorter than a thousand years, it is the cumulative emission of carbon-dioxide that drives climate change_-not the rate of emission. Consequently, as long as power stations and certain large industrial plants continue to burn fossil fuels, the only measure that it is available to prevent the produced carbon dioxide driving additional climate change is to capture and bury as much as possible underground, where it must stay for thousands of years if the whole exercise is to have any point.

It is therefore very important to develop carbon capture and storage (CCS), which has not yet been demonstrated in a complete large-scale system, and to understand better what it will cost, and how long the carbon will stay underground in different geological conditions. CCS is likely to be expensive, and whether-assuming it is feasible-it should then be deployed on a large scale will depend on the cost in comparison to alternative low carbon energy sources (unless the public is willing to pay for these alternatives, and/or pay over the odds for CCS, it would seem likely that most of the carbon in the world's remaining 'cheap' fossil fuels will be emitted into the atmosphere on a time scale of a (few) hundred years, with severe consequences for the climate).

\section{Necessary actions}

In addition to developing CCS (and rolling it out on a large scale, if it this is feasible, safe and affordable), meeting the energy challenge requires:

- Reducing energy use/improving efficiency, which can have a large impact and save a lot of money, as discussed further below, but is unlikely to do more than curb the rising growth in global energy, which is driven by rising living standards in the developing world.

- Developing and expanding low carbon energy sources; we need everything we can sensibly get, but I will argue that without major contributions from solar and/ or nuclear (fission and/or fusion) it will not be possible to replace the 14 TW currently provided by fossil fuels.

- Devising economic tools and ensuring the political will to make the above happen.

\section{Use of energy, demand reduction and energy efficiency}

Globally, energy use is shared: $31 \%$ industry, $31 \%$ transport, $27 \%$ residential buildings, $9 \%$ commerce and 
public service, $2 \%$ agriculture, forestry and fisheries, according to the Internal Energy Agency. Private use (in transport + buildings) is large, so although what we each do individually does not matter, what we do collectively is enormously important.

There is huge scope for reducing demand by, for example, designing buildings to make good use of natural light, and planning cities to encourage walking, bicycling or use of public transport. There are major opportunities in rapidly developing countries, where low-carbon development paths should be adopted as early as possible in planning expanding transport systems and cities (once a city ends up like Phoenix, going back is next to impossible). Changes in planning and procurement by cities and communities, designed to optimise energy use and reduce $\mathrm{CO}_{2}$ emissions, are increasingly important drivers of demand and efficiency.

Managing demand and matching multiple sources of supply and demand through a smart grid (which collects information on grid conditions, use and costs across a large network, with multiple connections, and bidirectional flows) is becoming increasingly important. This should lead to more efficient energy use and reduce costs by lowering peak demand on the grid, and will be necessary when the penetration of intermittent sources (wind, solar) increases to much above the $20 \%$ level.

Big efficiency gains are possible, from (e.g.) improved building insulation, more efficient lighting (which consumes $19 \%$ of the world's electricity), and more efficient internal combustion engines or moving to hybrids or electric cars. Energy consumption per unit of GDP has been falling (in the UK it is now $40 \%$ of the 1971 level) but GDP has been rising faster. Much more could be done while saving a lot of money (according to McKinsey, US $\mathrm{CO}_{2}$ emissions could be reduced by nearly $20 \%$ by actions which would all save money). It's not happening as fast might be expected because of:

- The 'rebound effect'-greater efficiency can lead to greater use. Similarly, trying to reduce demand by telling people how to save money and energy, e.g. by adjusting the thermostat, may lead them to conclude that they can afford to use more.

- Affluence in the developed world. Most of us don't care about relatively small savings, even if we know that collectively they could have a large effect-we need to be compelled to make them by regulations, e.g. on building construction and the performance of cars.

- Lack of capital in parts of the developing world, which may inhibit investment in efficient devices and solutions even if the pay-back time is short.

Reducing demand and improving efficiency are imperative. They can curb the $40 \%$ increase in world energy consumption expected by 2030, but it would be fanciful to think that they could produce an overall decrease. It is therefore vital, in parallel, to radically expand the use of low carbon energy sources.

\section{Low carbon energy sources}

It is interesting to ask: what can replace the $14 \mathrm{TW}$ (and rising) of primary power that the world derives from fossil fuels? The maximum additional potential of wind + hydro + bio + (enhanced) geothermal + marine energy appears to be no more than 6 or 7 TW [in detail: I think that the maximum additional practical, thermal equivalent, potentials are-wind $3 \mathrm{TW}(35 \times 2009$; about half today's global electricity generation), hydro 2 TW $(2 \times 2009)$, bio 1 TW (2/3 of 2009), (enhanced) geothermal 1 TW $(50 \times 2009)$, marine $0.1 \mathrm{TW}(600 \times 2009)]$. We should use as much of these sources of energy as we reasonably can, noting that (1) their potential contributions are very location dependent (none except wind seems to have much potential in the GCC countries), (2) this is easier said than done as most are currently more expensive than fossil fuels (ignoring externalities), and wind and marine (and solar) provide energy intermittently, and if used on a large scale need to be backed up by other sources, or supplemented by large scale energy storage systems which urgently need to be developed.

The conclusion is that if/when fossil fuels become unaffordable, or we renounce their use, solar and/or nuclear energy, which are not included in the list above, will have to play a major role.

\section{Solar energy}

Solar energy could in principle easily provide all the world's energy needs: with $15 \%$ efficiency (which is readily available from Photo Voltaic and Concentrated Solar Power), $0.5 \%$ of world's land surface could provide $20 \mathrm{TW}$ of electricity. However, although solar capacity has grown at an average of some $40 \%$ p.a. in the last decade, solar today only provides less than $0.01 \mathrm{TW}$ (compared to world electricity consumption of $2.4 \mathrm{TW}$ ) so there is a very long way to go. High priority should be given to driving down costs (which is happening) and developing storage (for use at night and when the sun is not shining: for CSP thermal storage is appropriate, and being used; for PV hydrogen, or hydrocarbons synthesised from $\mathrm{H}$ and $\mathrm{CO}_{2}$, could be used for storage and as an energy vector). Projects such as Desertec, which aims to supply Europe with solar and wind energy from $\mathrm{N}$ Africa, will require long distance high voltage DC transmission. The potential is of course 
large in the GCC countries, where solar energy can play a big role as a source of energy for desalination as well as electricity generation.

\section{Nuclear}

Nuclear and hydro are the only large-scale low-carbon sources of energy currently in use, apart from burning biomass that is renewed. However, while hydro-power could at most be expanded by a factor of about three globally, nuclear has a much bigger potential and in my opinion should be expanded now.

The first examples of a new improved generation of nuclear reactors are currently being built, but this is not happening as rapidly as might be hoped because of concerns about:

- the cost of nuclear power, which has been relatively high in the past (although less than that of coal or gas power if the environmental costs of burning fossil fuels are included). The cost depends strongly on the cost of borrowing the large sums needed to build reactors, which is generally higher than the cost of borrowing to invest in coal and gas plants because of the greater risks (of changes in government policy; being undercut by gas and coal in the future; delays in the planning process and/or construction; and cost over-runs). On paper, ${ }^{1}$ the new 'generation 3 ' reactors look competitive with coal, but construction of the first units is running late and going way over budget, and more construction experience is needed to establish the real cost.

- safety, which is mainly a problem of perception: objectively the safety record of nuclear power is good compared to that of almost all other major sources of power (although there is no room for complacency);

- disposal of waste, which is technically not an issue although reduction in the volume of waste needing long-term storage (which is possible-see below) would be helpful;

- proliferation, which is mainly a political issue.

Technically the rate at which nuclear power can be expanded is limited by lack of capacity. There are relatively few suppliers, and there is a need to expand the skills-base, which has been largely lost in countries such as the UK. At one time there were concerns about the availability of uranium, but it now seems that there is quite probably enough to provide for ten times current use for one hundred years at less than twice the current cost (which today only accounts for 2-4\% of the cost of nuclear electricity). This is long enough to further develop options that would prolong the nuclear age and could have some immediate benefits, including:

- re-cycling nuclear fuel (20\% more energy for a given amount of Uranium; less waste).

- fast breeder reactors (60 times as much energy/kg U, less waste, but more expensive, and slow to deploy-so development should not be delayed too long): fast breeders look promising as 'waste burners' to be used in conjunction with conventional reactors.

- thorium reactors (lots of it; less waste, but fuel fabrication much more demanding).

- fusion, which is intrinsically very attractive but extremely demanding.

\section{Conclusions on the global energy challenge}

Dealing with the enormous challenge will need a portfolio approach, which must include measures such as more solar, wind, hydro, bio and marine energy wherever sensible, and particularly: demand reduction, increased efficiency, more nuclear power, and (if feasible, safe and economically competitive) carbon capture and storage. In the longer term: the world will need much more solar power, advanced nuclear fission, and fusion power-if it can be made to work reliably and competitively.

There is a huge $\mathrm{R} \& \mathrm{D}$ agenda that requires more resources, which should be judged in comparison to the $\$ 400$ billion p.a. which is currently spent subsidising fossil fuels (subsidies for renewables are currently about $\$ 65$ billion p.a., while annual public funding of energy R\&D is about $\$ 25$ billion).

Above all there is a need for the political will to make a transition to a more energy efficient low carbon economy, which - as well as requiring the development of new and cheaper technologies - will have to be driven by financial incentives (especially a high carbon price) and tougher regulations of buildings, urban development and energy use.

Open Access This article is distributed under the terms of the Creative Commons Attribution License which permits any use, distribution, and reproduction in any medium, provided the original author(s) and the source are credited.
1 The Future of the Nuclear Fuel Cycle, MIT (ISBN 978-0-98280084-3) 2011.

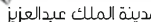

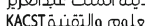

